Research Article

\title{
Contribution of WUSCHEL-related homeobox (WOX) genes to identify the phylogenetic relationships among Petunia species
}

\author{
Ana Lúcia Anversa Segatto ${ }^{1}$, Claudia Elizabeth Thompson $^{2}$ and Loreta Brandão Freitas ${ }^{1}$ \\ ${ }^{1}$ Laboratory of Molecular Evolution, Department of Genetics, Universidade Federal do Rio Grande do Sul \\ (UFRGS), Porto Alegre, RS, Brazil. \\ ${ }^{2}$ Center for Biotechnology, Department of Molecular Biology and Biotechnology, Universidade Federal do \\ Rio Grande do Sul (UFRGS), Porto Alegre, RS, Brazil.
}

\begin{abstract}
Developmental genes are believed to contribute to major changes during plant evolution, from infrageneric to higher levels. Due to their putative high sequence conservation, developmental genes are rarely used as molecular markers, and few studies including these sequences at low taxonomic levels exist. WUSCHEL-related homeobox genes $(W O X)$ are transcription factors exclusively present in plants and are involved in developmental processes. In this study, we characterized the infrageneric genetic variation of Petunia WOX genes. We obtained phylogenetic relationships consistent with other phylogenies based on nuclear markers, but with higher statistical support, resolution in terminals, and compatibility with flower morphological changes.
\end{abstract}

Keywords: molecular phylogeny, recently diverged species, developmental genes.

Received: March 21, 2016; Accepted: July 31, 2016.

\section{Introduction}

Flowering plants exhibit flower shapes that can be very different from one species to another in terms of their architecture. Adaptive radiation, referred as the rapid species diversification with increased phenotypic diversity (Schluter, 2000), has been proposed as an explanation for the high diversity observed in several plant species in some regions, especially those areas that have experienced rapid climatic or geological changes (Hughes and Eastwood, 2006). Species complexes originated from unstable areas could be of particular interest for evolutionary studies, but could also constitute a challenge. The morphological and phylogenetic species circumscription could be hampered by evolutionary processes such as, for example, recent or ancient gene flow (Hey, 2010), incomplete lineage sorting, or horizontal gene transfer (Knowles and Carstens, 2007). Petunia Juss. has undergone rapid diversification during the Pleistocene climatic changes (Lorenz-Lemke et al., 2010), and molecular phylogenies did not resolve all morphological species (Kulcheski et al., 2006; Chen et al., 2007; Reck-Kortmann et al., 2014).

Morphologically, the Petunia species may be divided into two main groups according to the corolla tube length.

Send correspondence to Loreta Brandão de Freitas. Laboratory of Molecular Evolution, Department of Genetics, UFRGS, P.O. Box 15053, 91501-970, Porto Alegre, RS, Brazil. E-mail: loreta.freitas@ufrgs.br
These groups have been supported in a multilocus phylogeny (Reck-Kortmann et al., 2014), despite the limited sequence divergence among species and indeterminate terminal positions. The long corolla tube group includes species with different floral syndromes (sphingophily, melittophily, and ornithophily) and several divergent morphological traits related to the pollinators, whereas among the species with a short corolla tube all are bee-pollinated (melittophily) and present fewer morphological differences among their flowers. Despite the morphologically homogeneous flowers, short corolla tube species present differences that could be attributed to developmental genes, such as corolla shape and adnation of floral pieces. All these attributes elect Petunia as one of the most diverse flower genera in Solanaceae Juss. (Knapp, 2010).

The WUSCHEL-related homeobox (WOX) gene family was first identified in Arabidopsis thaliana (L.) Heynh and posteriorly characterized in several plant species (Constanzo et al., 2014). Despite the WOX gene family being involved in flower development, these genes are present in algae but not in other eukaryotes outside the plant kingdom (Deveaux et al., 2008; Graaff et al., 2009). Studies have shown that the WOX gene family in the Petunia is dynamically involved in flower morphology and inflorescence determination, primarily coordinating cell proliferation (Stuurman et al., 2002; Rebocho et al., 2008; Vandenbussche et al., 2009; Constanzo et al., 2014). The diversity of flower morphology in Petunia, together with 
the availability of published studies describing $W O X$ genes in this genus, led us to choose this species to characterize $W O X$ variability at an infrageneric level. Seven $W O X$ genes were described in the genome of $P$. x hybrida (Hook.) Vilm. (Constanzo et al., 2014), and these genes are involved in different steps of flower and inflorescence architecture and development. For example, the $M A W$ gene (MAEWEST), an ortholog of AtWOX1 that is required for petal and carpel fusion and lateral growth of the leaf blade (Vandenbussche et al., 2009), presents different expression levels through the different developmental stages in wild Petunia species with short (P. inflata R.E.Fr.) and long corolla tubes [P. axillaris (Lam.) Britton, Sterns \& Poggenb.], indicating the possible participation of $M A W$ in the regulatory network that leads to different corolla morphologies (Segatto et al., 2013). Other well-characterized Petunia WOX genes are PhEVG (EVERGREEN) and PhSOE (SISTER OF EVERGREEN), both closely related to the AtWOX8 and AtWOX9 of A. thaliana. PhEVG and PhSOE were originated from a relatively recent event of duplication in $P$. x hybrida, but while $P h E V G$ is exclusively expressed in incipient lateral inflorescence meristems and it is essential for the specification of cymose inflorescence type in Petunia (Constanzo et al., 2014), PhSOE has different patterns of expression and it is most likely involved in the development of the shoot apical meristem (Rebocho et al., 2008). In this study, the $W O X$ genes were used to better understand the Petunia species evolutionary relationships.

\section{Material and Methods}

We analyzed partial sequences from 21 Petunia taxa (according to Ando et al., 2005a) and Calibrachoa parviflora (Jussieu) D'Arcy collected in southern Brazil, Argentina, and Uruguay (Figure 1A and Table S1) for the WOX genes of $P$. x hybrida (PhWUS, PhWOX1/MAW, PhWOX2, PhWOX3/PRS, PhWOX4, PhEVG, and PhSOE). The primers, designed with Primer3 0.4 (Rozen and Skaletsky, 2000) (Table S2), were 20-24 base pairs (bp) long and shared $100 \%$ homology with the $P$. $\mathrm{x}$ hybrida sequences. The TM of each primer was ca. $60^{\circ} \mathrm{C}$. Polymerase chain reaction (PCR) amplifications were performed in 25 $\mu \mathrm{L}$ reactions consisting of 1 unit of Platinum Taq polymerase (Invitrogen, Carlsbad, CA, USA), 1X Platinum Taq polymerase buffer (Invitrogen), $0.2 \mathrm{mM}$ of each dNTP, 0.2 $\mathrm{mM} \mathrm{MgCl}, 0.2 \mu \mathrm{M}$ of each primer, $5 \%$ of dimethyl sulfoxide (DMSO), and 20-50 ng of genomic DNA as a template. The following PCR conditions were used: $94{ }^{\circ} \mathrm{C}$ for 3 min for the initial denaturation of the fragments, 35 cycles of $30 \mathrm{~s}$ at $94{ }^{\circ} \mathrm{C}, 55^{\circ} \mathrm{C}$, and $72^{\circ} \mathrm{C}$ each, with a final extension step of $10 \mathrm{~min}$ at $72{ }^{\circ} \mathrm{C}$ to complete the synthesis. The PCR products were purified using $20 \%$ polyethylene glycol (Dunn and Blattner, 1987) and sequenced in a MegaBACE 1000 DNA Analysis System (GE Healthcare, Biosciences, Pittsburgh, PA, USA) using the ET Terminator Kit (GE
Healthcare) according to the manufacturer's instructions. As different members of the $W O X$ gene family are divergent outside the homeodomain region (Deveaux et al., 2008), this enabled us to sequence the genes in Petunia without cloning, by positioning the primers in adjacent regions of the homeodomain.

The obtained sequences were aligned using MUSCLE (Edgar, 2004) software as implemented in MEGA6 (Tamura et al., 2013) and then manually edited. We compared exon (including the homeodomain) and intron sequence diversity and their resulting phylogenies to characterize the WOX gene variation inside Petunia (see Table S1 for GenBank accession and voucher numbers). Heterozygous sites were standardized by the more frequent nucleotides in the position in all individuals and in all analyses. A site was identified as heterozygous when double peaks occurred in the identical position in both strands, with the weakest signal reaching at least $25 \%$ of the strength of the strongest (Fuertes Aguilar and Nieto Feliner, 2003). The nucleotide heterozygous sites never induced amino acid substitutions. Calibrachoa parviflora sequences were used as outgroups. We used jMODELTEST 2.1.4 (Posada, 2008) to determine the best evolutionary models for the DNA alignment, based on the Akaike Information Criterion (AIC). The best-fit model was the GTR (Generalized Time Reversible) with a discrete gammadistribution of rate variation across nucleotide sites. Bayesian Inference (BI) analyses were conducted using the MRBAYES 3.2.2 program (Ronquist and Huelsenbeck, 2003) with the previously described DNA evolutionary models and four chains were run for 10,000,000 generations, with $25 \%$ genealogies discarded as burn-in. The intron, exon, and total (intron + exon) WOX trees were estimated. The $\mathrm{C}+\mathrm{G}$ content, number of variable sites, and average nucleotide diversity per site $(\pi)$ were calculated using DNASP 5.00.03 (Rozas et al., 2003).

\section{Results}

The first introns of the genes WUS, WOX1, and WOX4 of the Petunia species were sequenced and concatenated, leading to the alignment of $792 \mathrm{bp}$. The exon-concatenated alignment was 2,454 bp long and consisted of partial sequences of the first exon of WUS, WOX2, and $W O X 3$, partial sequences of the first and second exon of $W O X 1$ and WOX4, and partial sequence of the second exon of $S O E$ and $E V G$ genes. The sequenced exon regions contained the homeodomain region for all previously described genes. Regarding the homeodomain region, almost all $W O X$ genes in Petunia shared the conserved sequence NVFYWFQN in the homeodomain helix region and only $S O E$ had the sequences NVFLLVSN or KCFLLVSN (Figure S1) that increase the percentage of neutral and aliphatic amino acids. The concatenated exons of the WUSCHEL-related homeobox exhibited higher $\mathrm{G}+\mathrm{C}$ content than the 


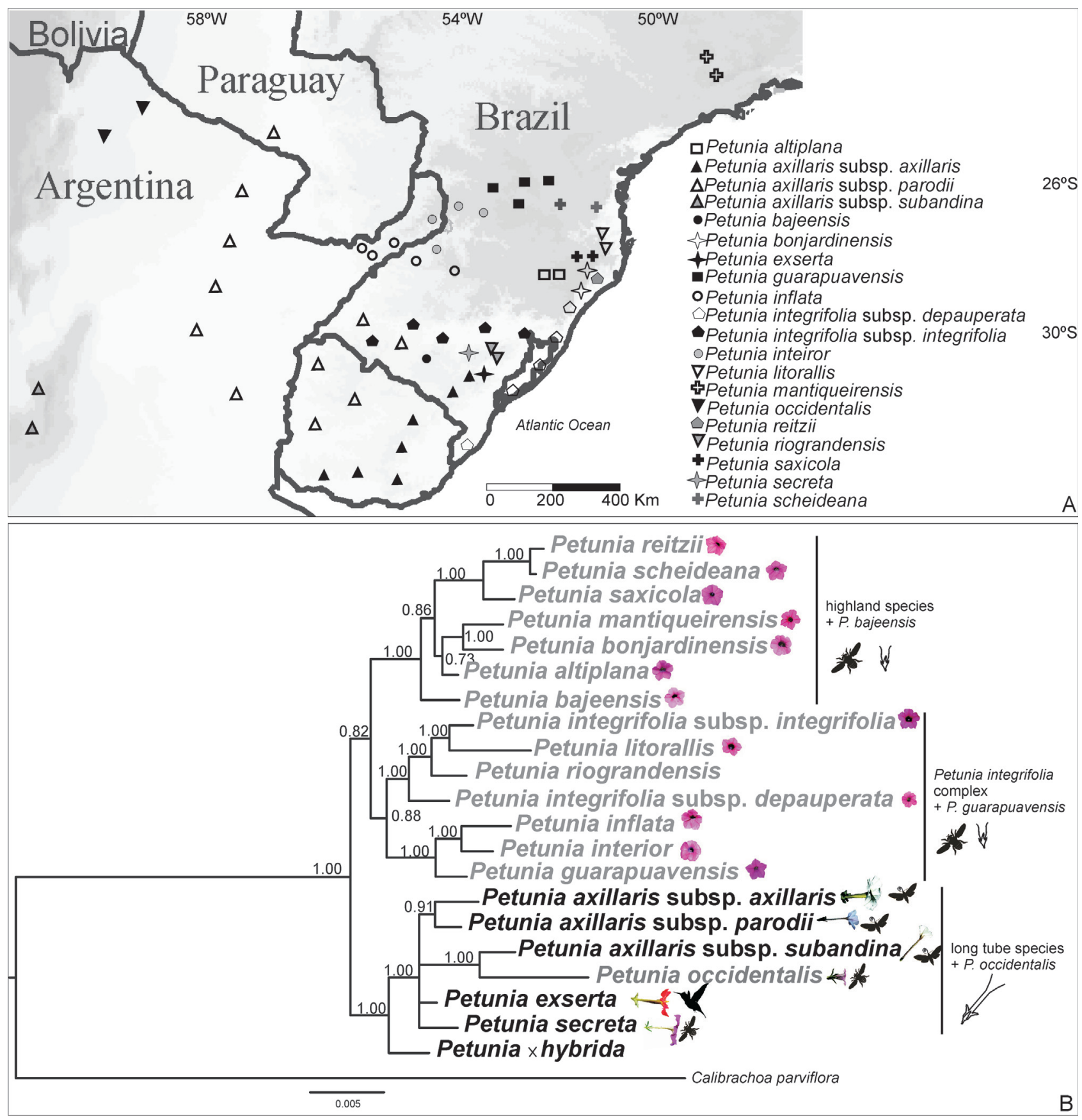

Figure 1 - Bayesian inference phylogeny and geographic distribution of Petunia species. (A) Schematic representation of Petunia geographic distribution. (B) Bayesian phylogenetic tree considering the intron/exon WUSCHEL-related homeobox gene sequences in Petunia species. The posterior probabilities are indicated above the branches. The short corolla tube species names are in gray, and the long corolla tube species are in black. Species pollinators are represented (bee, hawk-moth, and hummingbird).

concatenated introns and more polymorphic sites, but lower nucleotide diversity on average per site (Table 1). The intron, exon, and intron + exon datasets produced BI phylogenies with very similar topology (Figure S2), and the intron + exon tree presented the highest posterior probabilities for all branches (Figure 1B) that were similar to other phylogenetic propositions. Two main clades that correspond to species with short and long corolla tubes were re- covered in both intron + exon and intron-only trees, whereas in the exon-based tree the species presenting long corolla tube did not group. The majority of relationships between sister species was maintained in all trees, with exceptions corresponding to low-supported branches. Petunia $\mathrm{x}$ hybrida was positioned as a sister group of short tube species in the exon-only and intron-only trees and as a sister group of the long tube species in the intron + exon tree. In 
Table 1 - Petunia WOX genes sequence polymorphisms.

\begin{tabular}{lccc}
\hline & Exons & Introns & Exons + introns \\
\hline $\mathrm{G}+\mathrm{C}$ content & $39 \%$ & $26 \%$ & $37 \%$ \\
Number of variable sites & 108 & 34 & 142 \\
Average number of nucleotide diversity per site $(\pi)$ & $0.012 \pm 0.003$ & $0.026 \pm 0.005$ & $0.014 \pm 0.003$ \\
\hline
\end{tabular}

the intron + exon tree, Petunia bajeensis T.Ando \& Hashim., a microendemic species that occurs at altitudes below $200 \mathrm{~m}$, was the sister species of the group living in altitudes higher than $900 \mathrm{~m}$. Petunia guarapuavensis T.Ando \& Hashim. was closely related to $P$. inflata R.E.Fr. and $P$. interior T.Ando \& Hashim. in trees obtained with all datasets, even though $P$. guarapuavensis is morphologically more similar to $P$. scheideana L.B.Sm. \& Downs and does not occur in the same geographic region than $P$. interior and $P$. inflata (Figure 1A). This is the first time in Petunia phylogeny studies that the species $P$. riograndensis T.Ando \& Hashim. and P. integrifolia subsp. integrifolia and the species $P$. littoralis L.B.Sm. \& Downs and $P$. integrifolia subsp. depauperata (R.E.Fr.) Stehmann did not form homogeneous groups, respectively. Contrarily to the expected, the infraspecific taxa did not form closely related groups and this was observed in $P$. integrifolia and in $P$. axillaris subspecies, respectively. Petunia occidentalis R.E.Fr., a short corolla tube flowering species, was grouped into the long corolla tube clade (Figure 1B).

\section{Discussion}

In this work, we present a detailed evolutionary characterization of $W O X$ genes in wild Petunia species, aiming to highlight the contribution of the WUSCHEL gene family to phylogenetic studies. As a result of their high phenotypic diversity and rapid speciation (Lorenz-Lemke et al., 2010), Petunia species are an ideal model to examine evolutionary innovations and adaptation.

In Petunia, two main clades associated with corolla tube length are consistently obtained in molecular markerbased phylogenies (Chen et al., 2007; Kriedt et al., 2014; Reck-Kortmann et al., 2014), despite the low support in internal branches and uncertainty of some terminal positions. Flower morphology directly correlates with pollinator shift and has impacted Petunia diversification (Fregonezi et al., 2013). Similar results are consistently shown for several plant groups in which changes in the pollination system are involved in increasing the diversification rates at the macroevolutionary level (Kay and Sargent, 2009) and enlarging the polymorphisms at the microevolutionary scale (Bradshaw and Schemske, 2003; Dyer et al., 2007; Sheehan et al., 2016). Pollinator shift could be caused by few phenotypic modifications making it a rapid mechanism of reproductive isolation, but it is rare and probably occurs in highly specialized taxa. The adaptation to different environmental conditions or habitats, coupled with reproduc- tive isolation by floral isolation generates different selection pressures and can determine the success of the new lineage (Chase et al., 2010). The most contrasting phenotypic characteristics in Petunia are between the two main clades and within the long corolla tube clade. While in the short corolla tube clade species share the same pollinator, in the long corolla tube clade there are three different floral syndromes. It is probable that pollination change influenced Petunia diversification in different ways among and within clades. The differential expression of $W O X$ gene is associated with flower development and differentiation in at least two Petunia species with contrasting corolla tube length (Segatto et al., 2013).

Here, all datasets used to build the phylogenetic trees showed significant improvement at the branches support in comparison with previous used markers and analyses, indicating the utility of the $W O X$ genes as markers for understanding species evolution in Petunia. Considering the complete dataset (intron + exon), we observed two highly supported clades corresponding to short and long corolla tube length.

At a second level, two well-supported clades appear, dividing the short and purple corolla tube and bee-pollinated species: the first corresponds to highland species, plus $P$. bajeensis, and the second is composed of the $P$. integrifolia group (all taxa with morphological traits similar to $P$. integrifolia and described, at least once, as infraspecific taxon) plus $P$. guarapuavensis (Figure 1B). Petunia bajeensis, a species that occurs just in lowlands, was the sister group of the highland species (Figure 1B), confirming previous findings of phylogenies based on combined nuclear and plastid markers (Reck-Kortmann et al., 2014). However, such relationships were not observed in phylogenies obtained through plastid sequence analysis (Lorenz-Lemke et al., 2010) or plastid RFLP (Ando et al., 2005a), in which $P$. bajeensis is placed in the lowland group of species, or those based only on nuclear sequences (Chen et al., 2007; Kriedt et al., 2014), in which $P$. bajeensis is placed in the highland group, with different sister species. All highland species share morphological traits with $P$. bajeensis, especially the stamen filaments adnated up to half of the corolla tube (Stehmann et al., 2009). Events of hybridization and/or incomplete lineage sorting, added to different coalescence times of the markers as discussed below, could explain the contrasting phylogenetic results. However, P. bajeensis occurs in lowlands and in the middle of $P$. integrifolia subsp. integrifolia distribution, 
and it is difficult to draw a biogeographic scenario in which this species would have the last common ancestor with a highland species, based on the data we have at the moment.

The sub-clade corresponding to the $P$. integrifolia group plus $P$. guarapuavensis was observed for the first time, and the presence of $P$. guarapuavensis in this group finds support in the extensive morphological similarity between that species and P. inflata (Ando and Hashimoto, 1995). Despite that $P$. guarapuavensis and $P$. scheideana share several morphological traits and have a similar geographic distribution (Figure 1A), they occupy different branches in molecular biology-based analyses (Chen et al., 2007; Lorenz-Lemke et al., 2010; Reck-Kortmann et al., 2014). Ando et al. (2005b) suggested as valid the taxa $P$. integrifolia subsp. depauperata, $P$. littoralis, $P$. riograndensis, and $P$. integrifolia subsp. integrifolia because of the differences in their floral traits, but Stehmann and Bohs (2007) proposed grouping all individuals with morphology corresponding to $P$. integrifolia subsp. depauperata and $P$. littoralis under $P$. integrifolia subsp. depauperata. Posteriorly, Stehmann et al. (2009) suggested also the union of $P$. riograndensis and $P$. integrifolia subsp. integrifolia under the latter taxa, justifying this choice with the association of several characteristics to the different environments where these plants grow. Previous evolutionary approaches (Longo et al., 2014; Reck-Kortmann et al., 2014; Ramos-Fregonezi et al., 2015) have supported the suggestions of Stehmann and Bohs (2007) and Stehmann et al. (2009), but the genetic variation found in WOX genes reinforces the proposition of Ando et al. (2005a,b), this indicating the need for more studies including these different morphologies.

In the second main clade, Petunia occidentalis, which has a short corolla tube, was grouped with the long corolla tube species. Previous studies observed similar phylogenies using nuclear sequences only (FLAVONOID-3',5'HYDROXYLASE gene, Chen et al., 2007; Tnt1 mobile elements, Kriedt et al., 2014) and nuclear + plastid markers (Reck-Kortmann et al., 2014). Petunia occidentalis presents a disjunct geographical distribution compared to other short corolla tube Petunia species (Figure 1). Therefore, it is not surprising that $P$. occidentalis $W O X$ genes exhibit a distinct evolutionary history. All Petunia phylogenies based on nuclear markers show a more recent common ancestor between $P$. occidentalis and the long corolla tube group. Different gene trees can diverge as a consequence of several factors, including horizontal transfer, lineage sorting, gene duplication, and extinction events (Maddison, 1997; Nichols, 2001).

Molecular phylogenies based on plastid-derived markers (Ando et al., 2005a; Kulcheski et al., 2006; Lorenz-Lemke et al., 2010) have proposed that the separation among Petunia species was related to the altitude of their occurrence, independent of corolla morphology. Nuclear and plastid genes have different coalescence times and, generally, organelle markers are geographically structured and more easily shared by different species (Chan and Levin, 2005; Mir et al., 2009), as observed in some Petunia species (Segatto et al., 2014). Therefore, it is not surprising that the trees based on WOX genes indicate an evolutionary history that is compatible with others obtained from nuclear information. The specific clades presented are contingent on corolla tube length, particularly because $W O X$ genes are involved in floral development and, at least with respect to the $M A W$ gene, are differentially expressed in Petunia species of different floral morphology (Segatto et al., 2013).

All WOX genes, including SOE, were most likely present in the last common ancestor of the genus. The use of WOX genes as molecular markers to reconstruct Petunia phylogeny resulted in a better-supported tree that was congruent with other published phylogenies for nuclear genes. The structure of $W O X$ proteins has also contributed to the understanding of molecular evolution and function of these genes in Petunia and in the whole Solanaceae family, as well (Stuurman et al., 2002; Rebocho et al., 2008; Vandenbussche et al., 2009; Tadeg et al., 2011; Segatto et al., 2013). In this context, we found a modification in the amino acid content of helix three of the homeodomain region in Petunia SOE genes. This helix contacts DNA and has a high level of basic amino acids, which makes it potentially important for nuclear localization (Li et al., 2014). SOE is not functionally characterized in Petunia but is expressed on the vegetative apex between the shoot apical meristem and leaf primordia, and later in the outermost cells of the placenta where the ovules are formed (Rebocho et al., 2008). SOE is also expressed in the basal end of young embryos, similar to AthWOX9 and AthWOX8 (Haecker et al., 2004; Rebocho et al., 2008). The amino acid substitution in helix three of the homeodomain may influence the SOE interaction with DNA and/or other transcription factors. Until now, no other $W O X$ genes have been described with this modification in helix three. Moreover, this region is strongly conserved in all other WOX genes. Consequently, the $S O E$ gene warrants further study to evaluate the effects of changes in helix three, cellular localization, and interaction with DNA and other transcription factors, which are, according to evolutionary developmental biology, master keys in evolution. Thus, the characterization of these transcription factors at different taxonomic levels is important to determine sequence conservation, reveal response to different selective pressures, and gene losses after species divergence, resulting in differences in morphological phenotype.

In this study, we characterized the $W O X$ transcription gene family in the genus Petunia and demonstrated the potential for the use of these genes as molecular markers to reconstruct infrageneric phylogenies. The use of species with significant morphological diversity in the study of the evolutionary dynamics of developmental genes is an interest- 
ing research strategy that can be expanded to other developmental genes and botanical families.

\section{Acknowledgments}

This work was supported by the Conselho Nacional de Desenvolvimento Científico e Tecnológico (CNPq), Coordenação de Aperfeiçoamento de Pessoal de Nível Superior (CAPES), and Programa de Pós-Graduação em Genética e Biologia Molecular - Universidade Federal do Rio Grande do Sul (PPGBM-UFRGS).

\section{References}

Ando T and Hashimoto G (1995) Petunia guarapuavensis Solanaceae: A new species from planalto of Santa Catarina, Brazil. Brittonia 47:328-334.

Ando T, Kokubun H, Watanabe H, Tanaka N, Yukawa T, Hashimoto G, Marchesi E, Suárez E and Basualdo I (2005a) Phylogenetic analysis of Petunia sensu Jussieu (Solanaceae) using chloroplast DNA RFLP. Ann Bot 96:289-297.

Ando T, Ishikawa N, Watanabe H, Kokubun H, Yanagisawa Y, Shimoto G, Marchesi E and Suárez E (2005b) A morphological study of the Petunia integrifolia complex (Solanaceae). Ann Bot 96:887-900.

Bradshaw HDJ and Schemske DW (2003) Allele substitution at a flower color locus produces a pollinator shift in monkeyflowers. Nature 426:176-178.

Chan KMA and Levin SA (2005) Leaky prezygotic isolation and porous genomes: Rapid introgression of maternally inherited DNA. Evolution 59:720-729.

Chase MW, Paun O and Fay MF (2010) Hybridization and speciation in angiosperms: A role for pollinator shifts? BMC Biol 8:e45.

Chen S, Matsubara K, Kokubun H, Kodama H, Watanabe H, Marchesi E and Ando T (2007) Phylogenetic analysis of the genus Petunia (Solanaceae) based on the sequence of the Hfl gene. J Plant Res 120:385-397.

Constanzo E, Trehin C and Vandenbussche M (2014) The role of WOX genes in flower development. Ann Bot 114:15451553.

Deveaux Y, Toffano-Nioche C, Claisse G, Thareau V, Morin H, Laufs P, Moreau H, Kreis M and Lecharny A (2008) Genes of the most conserved WOX clade in plants affect root and flower development in Arabidopsis. BMC Evol Biol 8:e291.

Dunn IS and Blattner FR (1987) Charons 36 to 40: Multi-enzyme, high capacity, recombination deficient replacement vectors with polylinkers and polystuffers. Nucleic Acids Res 15:2677-2698.

Dyer A, Whitney H, Arnold S, Glover B and Chittka L (2007) Mutations perturbing petal cell shape and anthocyanin synthesis influence bumblebee perception of Antirrhinum majus flower colour. Arthropod-Plant Interact 1:45-55.

Edgar RC (2004) MUSCLE: A multiple sequence alignment method with reduced time and space complexity. BMC Bioinformatics 5:e113.

Fregonezi JN, Turchetto C, Bonatto SL and Freitas LB (2013) Biogeographical history and diversification of Petunia and Calibrachoa (Solanaceae) in the Neotropical Pampas grassland. Bot J Linn Soc 171:140-153.
Fuertes Aguilar J and Nieto Feliner G (2003) Additive polymorphisms and reticulation in an ITS phylogeny of thrifts Armeria (Plumbaginaceae). Mol Phylogenet Evol 28:430447.

Graaff E, Laux T and Rensing SA (2009) The WUS homeoboxcontaining WOX protein family. Genome Biol 10:e248.

Haecker A, Gross-Hardt R, Geiges B, Sarkar A, Breuniger H, Hermann M and Laux T (2004) Expression dynamics of WOX genes mark cell fate decisions during early embryonic patterning in Arabidopsis thaliana. Development 131:657668.

Hey J (2010) The divergence of Chimpazee species and subspecies as revealed in multipopulation isolation-with migration analyses. Mol Biol Evol 27:921-933.

Hughes C and Eastwood R (2006) Island radiation on a continental scale: Exceptional rates of plant diversification after uplift of the Andes. Proc Natl Acad Sci U S A 103:1033410339.

Kay KM and Sargent RD (2009) The role of animal pollination in plant speciation: Integrating ecology, geography, and genetics. Annu Rev Ecol Evol Syst 40:637-656.

Knapp S (2010) On 'various contrivances': Pollination, phylogeny and flower form in the Solanaceae. Phil Trans R Soc B Biol Sci 365:449-460.

Knowles LL and Carstens BC (2007) Delimiting species without monophyletic gene trees. Syst Biol 56:887-895.

Kriedt RA, Cruz GMQ, Bonatto SL and Freitas LB (2014) Novel transposable elements in Solanaceae: Evolutionary relationships among Tnt1-related sequences in wild Petunia species. Plant Mol Biol Rep 32:142-152.

Kulcheski FR, Muschner VC, Lorenz-Lemke AP, Stehmann JR, Bonatto SL, Salzano FM and Freitas LB (2006) Molecular phylogenetic analysis of Petunia Juss. (Solanaceae). Genetica 126:3-14.

Li Z, Jiang H, Zhou L, Deng L, Lin Y, Peng X, Yan H and Cheng B (2014) Molecular evolution of the HD-ZIP I gene family in legume genomes. Gene 533:218-228.

Longo D, Lorenz-Lemke AP, Mäder G, Bonatto SL and Freitas LB (2014) Phylogeography of the Petunia integrifolia complex in southern Brazil. Bot J Linn Soc 174:199-213.

Lorenz-Lemke AP, Togni PD, Mäder G, Kriedt RA, Stehmann JR, Salzano FM, Bonatto SL and Freitas LB (2010) Diversification of plant species in a subtropical region of eastern South American highlands: A phylogeographic perspective on native Petunia (Solanaceae). Mol Ecol 19:5240-5251.

Maddison WP (1997) Gene trees in species trees. Syst Biol 46:523-536.

Mir C, Jarne P, Sarda V, Bonin A and Lumaret R (2009) Contrasting nuclear and cytoplasmic exchanges between phylogenetically distant oak species (Quercus suber L. and Q. ilex L.) in Southern France: Inferring crosses and dynamics. Plant Biol 11:213-226.

Nichols R (2001) Gene trees and species trees are not the same. Trends Ecol Evol 16:358-364.

Posada D (2008) jModelTest: Phylogenetic model averaging. Mol Biol Evol 25:1253-1256.

Ramos-Fregonezi AMC, Fregonezi JN, Cybis GB, Fagundes NJR, Bonatto SL and Freitas LB (2015) Were sea level changes during the Pleistocene in the South Atlantic Coastal Plain a driver of speciation in Petunia (Solanaceae)? BMC Evol Biol 15:e92. 
Rebocho AB, Bliek M, Kusters E, Castel R, Procissi A and Roobeek I (2008) Role of EVERGREEN in the development of the cymose Petunia inflorescence. Dev Cell 15:437-447.

Reck-Kortmann M, Silva-Arias GA, Segatto ALA, Mäder G, Bonatto SL and Freitas LB (2014) Multilocus phylogeny reconstruction: New insights into the evolutionary history of the genus Petunia. Mol Phylogenet Evol 8:19-28.

Ronquist F and Huelsenbeck JP (2003) MrBayes 3: Bayesian phylogenetic inference under mixed models. Bioinformatics 19:1572-1574.

Rozas J, Sanchez-Del Barrio JC, Messeguer X and Rozas R (2003) DnaSP, DNA polymorphism analyses by the coalescent and other methods. Bioinformatics 19:2496-2497.

Rozen S and Skaletsky HJ (2000) Primer3 on the WWW for general users and for biologist programmers. In: Krawetz $\mathrm{S}$ and Misener S (eds) Bioinformatics Methods and Protocols: Methods in Molecular Biology. Humana Press, New Jersey, pp 365-386.

Schluter D (2000) The Ecology of Adaptive Radiation. Oxford University Press, Oxford, 296 p.

Sheehan H, Moser M, Klahre U, Esfeld K, Dell'Olivo A, Mandel T, Metzger S, Vandenbussche M, Freitas L and Kuhlemeier C (2016) MYB-FL controls gain and loss of floral UV absorbance, a key trait affecting pollinator preference and reproductive isolation. Nat Genet 48:159-169.

Segatto ALA, Turchetto-Zolet AC, Aizza LC, Monte-Bello CC, Dornelas MC, Margis R and Freitas LB (2013) MAEWEST expression in flower development of two Petunia species. Int J Mol Sci 14:13796-13807.

Segatto ALA, Cazé ALR, Turchetto C, Klahre U, Kuhlemeier C, Bonatto SL and Freitas LB (2014) Nuclear and plastid markers reveal the persistence of genetic identity: A new perspective on the evolutionary history of Petunia exserta. Mol Phylogenet Evol 70:504-512.

Stehmann JR and Bohs L (2007) Nuevas combinaciones en Solanaceae. Darwiniana 45:240-241.
Stehmann JR, Lorenz-Lemke AP, Freitas LB and Semir J (2009) The genus Petunia. In: Gerats T and Strommer J (eds) Petunia: Evolutionary, Developmental and Physiological Genetics. 2nd edition. Springer, New York, pp 1-28.

Stuurman J, Jaggi F and Kuhlemeier C (2002) Shoot meristem maintenance is controlled by a GRAS-gene mediated signal from differentiating cells. Genes Dev 16:2213-2218.

Tadeg M, Lin H, Bedair M, Berbel A, Wen J, Rojas CM, Niu L, Tang Y, Sumner L, Ratet P, et al. (2011) STENOFOLIA regulates blade outgrowth and leaf vascular patterning in Medicago truncatula and Nicotiana sylvestris. Plant Cell 23:2125-2142.

Tamura K, Stecher G, Peterson D, Filipski A and Kumar S (2013) MEGA6: Molecular Evolutionary Genetics Analysis version 6.0. Mol Biol Evol 30:2725-2729.

Vandenbussche M, Horstman A, Zethof J, Koes R, Rijpkema AS and Gerats T (2009) Differential recruitment of WOX transcription factors for lateral development and organ fusion in Petunia and Arabidopsis. Plant Cell 21:2269-2283.

\section{Supplementary material}

The following online material is available for this article:

Figure S1 - Alignment of the Petunia homeodomain region of WUSCHEL-related homeobox genes.

Figure S2 - Bayesian inference phylogenies of WUSCHEL-related homeobox gene sequences in Petunia species.

Table S1 - Petunia WUSCHEL-related homeobox gene sequence information.

Table S2 - Sequences of the primers used in this work.

Associate Editor: Louis Bernard Klaczko

License information: This is an open-access article distributed under the terms of the Creative Commons Attribution License (type CC-BY), which permits unrestricted use, distribution and reproduction in any medium, provided the original article is properly cited. 